\title{
Conflictos de valoración y uso del patrimonio religioso con fines turísticos en el centro histórico de la ciudad de Toluca, México
}

Recibido: 24/10/17 · Aceptado: 16/06/18

\author{
Carlos Antonio Rosas Candelas* \\ Centro Universitario UAEM Temascaltepec \\ Universidad Autónoma del Estado de México \\ Andrés López Ojeda \\ Héctor Javier Favila Cisneros \\ Ricardo Hernández López \\ Facultad de Turismo y Gastronomía \\ Universidad Autónoma del Estado de México
}

\section{RESUMEN}

El texto tiene como objetivo un acercamiento general a la manera en que se lleva a cabo la gestión del patrimonio religioso con fines turísticos en el centro histórico de la ciudad de Toluca, México. Se considera su valoración en términos de sus alcances, problemáticas y limitaciones, con base en el marco explicativo de Thompson (2006), quien argumenta que una consecuencia de la contextualización de las formas simbólicas es que están sujetas a complejos procesos de evaluación y conflicto, distinguiéndose dos tipos de valoración particularmente importantes: la simbólica y la económica. Se parte de la hipótesis de que la gestión de los bienes patrimoniales religiosos orientados al turismo constituye un campo de disputa simbólica y funcional entre los diversos grupos de interés involucrados, que conlleva una gestión diferenciada derivada de los distintos tipos de apropiación del patrimonio, lo cual incide en su aprovechamiento.

Palabras Clave: Gestión del patrimonio, turismo religioso, turismo cultural, usos y valoración del patrimonio.

*Correos electrónicos: met.carlos.rosas@gmail.com · alopezoj@uaemex.mx · hfavilac@uaemex.mx·riherlo@hotmail.com 


\section{Conflicts of valuing heritage assets and use of religious heritage for tourism purposes in Toluca City, Mexico}

\section{Abstract}

Carlos Antonio Rosas Candelas*

Centro Universitario UAEM Temascaltepec Universidad Autónoma del Estado de México

Andrés López Ojeda Héctor Javier Favila Cisneros Ricardo Hernández López Facultad de Turismo y Gastronomía

The paper aims to a general approach to the way in which the management of religious heritage is carried out for tourism purposes in the historic center of the city of Toluca, Mexico. Assessment it considered according to the scope problems and limitations, based on the explanatory framework of Thomson (2006) who argues that one consequence of the contextualization of symbolic forms is that they are subject to complex processes of evaluation and conflict, distinguishing two types of particularly important assessments: the symbolic and economic ones. The hypothesis is that the management of the religious assets oriented towards tourism, constitutes a field for symbolic and functional dispute between the various interest groups involved, which entail the different management style according to the different types of appropriation of heritage that has an impact on their use.

KEY WORDS: Heritage management, religious tourism, cultural tourism, uses and heritage assessment.

*E-mail: met.carlos.rosas@gmail.com·alopezoj@uaemex.mx · hfavilac@uaemex.mx·riherlo@hotmail.com 


\section{Introducción}

Desde tiempos ancestrales, los desplazamientos por motivos de fervor y devoción religiosos han estado presentes en la humanidad, sin importar género, edad o estrato social. En la actualidad, millones de peregrinos realizan cada año este tipo de viajes a diversos y muy variados santuarios; los motivos que encierran son distintos: hacer una ofrenda, pedir un favor o simplemente cumplir con la tradición. En este sentido, el patrimonio religioso puede representar una oportunidad considerable para el desarrollo de actividades turísticas, ya que los visitantes interesados resultan ser turistas fieles y más recurrentes a los destinos.

A las peregrinaciones a los "lugares santos", en diferentes santuarios, principalmente en Europa y América, se han agregado servicios diversos a fin de motivar una mayor estancia para el disfrute de la infraestructura cultural y otras actividades de ocio y entretenimiento (museos, teatros, recorridos especiales y actividades alternas), sin mucha contradicción en relación con sus creencias.

No obstante, en muchos casos, los servicios se ofertan sin planearse, solo atendiendo una necesidad inmediata o básica, de manera que los negocios no cuentan con estándares de calidad, no resultan idóneos de acuerdo con los perfiles de los visitantes (Robles, 2001) y, menos aún, se visualizan los impactos que todo esto puede tener en la comunidad y en la población local.

Si bien existe literatura especializada que aborda al turismo religioso y la gestión del patrimonio como objetos de estudio (Gamboa, 2016; Chavolla, 2014; Fernández, 2012; entre otros), buena parte de ella se ha enfocado a delinear los perfiles de los visitantes en busca de saber los motivos específicos que los llevan a realizar este tipo de desplazamientos; en otro sentido, se conoce menos o no se ha estudiado concretamente el manejo del patrimonio, es decir, la forma en que el patrimonio religioso es utilizado, apropiado, valorado y aprovechado por parte de encargados, promotores, prestadores de servicios turísticos, entre otros actores, que se encuentran involucrados.

De tal manera, el presente trabajo de corte etnográfico, llevado a cabo en la ciudad de Toluca, México, tiene por objetivo plantear grosso modo la problemática que se deriva del uso y manejo de los bienes patrimoniales. Para ello se realiza una aproximación a las visiones del patrimonio que inciden en la forma en que este se valora, se apropia y se utiliza. Se discute el uso de un modelo 
de gestión centrado en la generación de "rentabilidad social”, que considera no solo la dimensión económica, sino también la pertinencia de salvaguardar el patrimonio, sin que ello signifique la ausencia de conflicto y contradicciones. Así como un esquema que intenta diferenciar las valoraciones que le otorgan los principales grupos de interés involucrados en relación con el uso y aprovechamiento del patrimonio religioso. Entre las conclusiones que se pueden destacar se encuentran las siguientes: el patrimonio religioso se ha empezado a incorporar a la oferta turística de la localidad, sin embargo, no se han diseñado estrategias transversales que integren a la totalidad de grupos interesados en su manejo; las estrategias ya implementadas tienen metas específicas de acuerdo a cada grupo de interés, por lo que estas se contraponen y obstaculizan el trabajo de los otros; mientras tanto, la demanda turística ha comenzado a voltear la mirada hacia el patrimonio religioso de la ciudad y los bienes que lo integran.

\section{Patrimonio, turismo y bienes culturales religiosos}

El patrimonio con el que cuenta cada localidad es un elemento a partir del cual se puede acceder a las formas de pensar, de sentir y de vivir de las personas que habitan ahí, por lo tanto, tales expresiones (tanto materiales como inmateriales) pueden resultar atractivas no solo para conocerlas debido a sus dimensiones estéticas, históricas o culturales, sino también como un dispositivo cognoscitivo más amplio que puede dar cuenta de discusiones acaso más importantes como puede ser la caracterización de la identidad de una comunidad, su ethos y filosofía, sus valores y forma de ver el mundo (Parker y Moreno, 2015; Elbez, 2017).

Los bienes patrimoniales representan un campo relevante desde hace mucho tiempo en México, debido a que son elementos vinculados con la identidad cultural local, regional o nacional. Resultan de tal importancia que constituyen una dimensión de política pública a cargo, básicamente, del Instituto Nacional de Antropología e Historia (INAH) y del Instituto Nacional de Bellas Artes (INBA), así como de interés internacional (Organización de las Naciones Unidas para la Educación, la Ciencia y la Cultura -Unesco-, Consejo Internacional de Monumentos y Sitios -Icomos-). Para el caso del turismo, el patrimonio aparece por lo general como una fuente de ingresos significativa, en especial para los 
prestadores de servicios y la población local involucrada, como lo demuestra la encuesta de gasto turístico de la Secretaría de Turismo (Sectur, 2013; López, 2015), donde se registra que 8.5 millones de personas se desplazan por motivaciones culturales (turismo cultural); $52 \%$ lo hace por su preferencia hacia el patrimonio intangible, así como 594339 visitantes extranjeros, por la misma motivación. Se agrega que 9 \% se encuentra interesado en conocer lugares que cuentan con patrimonio intangible.

Lo anterior es coherente con el auge que, desde hace algún tiempo, mantiene el llamado turismo cultural, el cual se entiende como "aquel viaje turístico motivado por conocer, comprender y disfrutar el conjunto de rasgos y elementos distintivos, espirituales y materiales, intelectuales y afectivos que caracterizan a una sociedad o grupo social de un destino específico" (Sectur, 2015, s. p.). Dentro de esta modalidad se encuentra aquella que se refiere específicamente a esos desplazamientos que realizan las personas hacia lugares de adoración, de fe, etc., a la cual, de manera genérica, se define como turismo religioso.

Este llamado turismo religioso genera, en el nivel internacional, el desplazamiento de 300 millones de personas. México se encuentra dentro de los países que más turistas reciben por esta modalidad turística, ya que se estima que son alrededor de 30 millones de personas las que realizan algún tipo de desplazamiento de este tipo (Cámara de Diputados, 2016). Esto último debido a que México cuenta con una tradición religiosa, lugares de peregrinaje y bienes de gran importancia histórica, estética y arquitectónica, como pueden ser la gama de templos existentes, entre los cuales sobresale la Basílica de Guadalupe (Ciudad de México), que genera desplazamientos de 15 millones de personas anualmente. Otros santuarios que motivan una intensa llegada de personas son el templo de la Virgen de San Juan de los Lagos (Jalisco), con siete millones de visitantes cada año, y el santuario del Santo Niño de Atocha (Zacatecas) y el templo de Cristo Rey (Guanajuato), a los cuales acuden 2.5 millones de feligreses (Cámara de Diputados, 2016).

En el caso del Estado de México, el principal destino religioso es Chalma, con dos millones y medio de visitantes (Cámara de Diputados, 2016; Osorio et al., 2016), sin embargo, también existen otros lugares que cuentan con diversos bienes religiosos (festividades, prácticas, bienes inmuebles, tradiciones, etc.), de los cuales, sin embargo, se tienen datos escasos. Respecto a la ciudad de 
Toluca, poco se ha estudiado la forma en que los bienes y las fiestas religiosas populares pueden constituir un recurso turístico, y, aunque ya hay estrategias para promocionarlos con fines turísticos, en realidad poco se sabe sobre la manera en que los distintos grupos de interés usan y se apropian del patrimonio, es decir, sobre cómo se gestiona ese tipo de bienes, sus alcances, sus problemáticas y la participación de los diferentes grupos sociales en términos de su aprovechamiento, valoración y uso.

\section{Visiones del patrimonio y la gestión cultural como modelo de análisis}

El patrimonio cultural, a lo largo de los años y con base en un breve acercamiento al estado del conocimiento, ha sido visualizado desde tres enfoques principales:

a) El primero podemos denominarlo conservacionista, en el cual se tiende a sacralizar el patrimonio, considerándolo como un bien cultural que proporciona identidad a la comunidad local. En este enfoque se privilegia el acceso y la educación del patrimonio (instituciones públicas nacionales), se le da una gran relevancia a su aportación como parte de la identidad cultural (instituciones internacionales). Esta perspectiva es, en su mayoría, de carácter antropológico y predomina en la visión de diversas instituciones internacionales y nacionales como la Unesco, el INAH, el INBA y diversas organizaciones no gubernamentales. Se relega entonces la incorporación de un nuevo uso a tales bienes, es decir, el patrimonio se fetichiza como elemento que no puede ser tocado ni utilizado para algún otro fin que no sea el de la contemplación, por lo que debe protegerse y conservarse. En esta visión, el turismo no tiene cabida por las alteraciones (pérdida o destrucción) que, como consecuencia de aquél, pudieran derivarse.

b) El segundo entiende al patrimonio desde una visión práctica o funcional; subyace la idea de que este es una construcción social y cultural que puede ser utilizado y aprovechado con un nuevo uso (particularmente importante para el turismo). En esta perspectiva se enmarca la mayoría de las investigaciones realizadas con un enfoque economicista, donde se considera al 
patrimonio un recurso cultural capaz de generar rentabilidad privada y desarrollo a la población local. Esta mirada es compartida por instituciones de carácter global y nacional como la Organización Mundial del Turismo, la Sectur y la iniciativa privada. Una polémica en relación con tal visión es que, al priorizar la rentabilidad económica sobre el patrimonio, estos bienes tienden a ser mercantilizados, se escenifican y comienza un proceso en el que se desvirtúa su significado originario, es decir, el patrimonio se pone al servicio de los "consumidores culturales", con el riesgo de transformarse en un mero producto.

3) El tercero se caracteriza por una visión mixta, ya que señala que el patrimonio es capaz de contar con múltiples funciones, reconociéndolo, por un lado, como una herencia (cultural), y, por el otro, como un recurso que puede ser aprovechado para generar una rentabilidad económica y social en beneficio de la localidad y de los mismos bienes culturales; considera la posibilidad de vincular y conciliar objetivos comunes de los distintos grupos de interés en el patrimonio (empresarios, turistas, instituciones públicas y ciudadanas, por ejemplo).

Con base en lo anterior, una pregunta pertinente puede ser: ¿De qué manera se puede comenzar a discutir el uso y aprovechamiento del patrimonio religioso con una orientación turística en un campo donde se mezclan visiones que a veces son opuestas y otras complementarias respecto a bienes que, en unos casos, se encuentran consagrados y, en otros, aparecen como cualquier mercancía?

Esta problemática puede repensarse a partir del concepto de gestión del patrimonio, el cual, en general, significa considerar una actuación integral orientada a optimizar tales bienes y recursos para obtener una ganancia en términos de "rentabilidad social y económica" y, al mismo tiempo, con la posibilidad de tener en cuenta los intereses de los distintos grupos involucrados (Bermúdez, Arbeloa y Giralt, 2004; Santillán y Olmos, 2004; Querol, 2010).

La primera idea, entonces, se refiere a la necesidad de pensar en un manejo y uso inclusivo del patrimonio, pero con una perspectiva social que considere aspectos como su rentabilidad, además de acciones para su conservación, protección y didáctica, es decir, dirigirse al logro de una gestión integral de bienes y recursos de una clase muy especial, como aquellos que conforman la 
cultura de una sociedad. Ahora bien, este último propósito por lo común tiende a obtener un consenso general, incluso, en la mayoría de los casos y las experiencias se considera benéfico realizar acciones que favorezcan la conservación del patrimonio, sin embargo, hay que reconocer que los bienes patrimoniales también constituyen un campo en disputa que puede ayudarnos a explicar la fragmentación y las direcciones que toman las visiones y los esfuerzos de los grupos que participan en su manejo y aprovechamiento, como se detallará en el siguiente apartado.

\section{Axiología del patrimonio y la apropiación diferenciada}

La riqueza cultural de una sociedad viene determinada tanto por sus bienes tangibles (monumentos, templos, edificaciones) como intangibles (costumbres, saberes, manifestaciones lúdicas y festivas). En términos amplios, al conjunto de estos bienes y manifestaciones se le conoce como patrimonio cultural. Este concepto incluye no solo el patrimonio histórico, sino también otras manifestaciones como la lengua, la literatura, las artesanías, la gastronomía, la religión, etc. Este patrimonio, desde nuestro punto de vista, engloba la herencia cultural de una sociedad, los productos artísticos y creativos, pero además se puede convertir en un recurso estratégico capaz de generar desarrollo centrado en las personas y en las comunidades (Unesco, 1982 y 2005).

En la actualidad, un segmento importante de turistas busca nuevas experiencias para enriquecerse personalmente interesándose, por lo regular, en lugares con una cultura local distintiva, así como un acercamiento hacia la naturaleza (turismo de naturaleza). Esto explica una tendencia a la alza del turismo cultural y todo un esfuerzo por incorporar al mercado de los viajes los activos patrimoniales teniendo como estrategia las tareas de difundirlos, planificarlos e integrarlos como instrumentos de comunicación y comprensión de la cultura de un pueblo, de manera que se incida en la forma tradicional en que se han incorporado a la oferta turística, es decir, solo por su valor de uso económico, lo cual aparece como una visión muy restringida, ya que la articulación turistacomunidad implica una interacción donde se intercambian ideas, estilos de vida y aspectos culturales, confrontándose diferentes percepciones de lo que se está viviendo (Andrade, 2009). 
Por otra parte, los bienes que integran el patrimonio cultural son utilizados como recursos que constituyen o complementan los servicios añadiendo nuevas ofertas de carácter lúdico y recreativo para los visitantes. El turismo, en cuanto se integra profundamente en la economía de los países, puede convertirse en uno de los principales motores que potencializan la revalorización del patrimonio cultural, como sucede, por ejemplo, en Las Peñas, Ecuador, donde a partir de una intervención gubernamental y privada, un lugar marginal pero con un componente histórico importante al constituir el primer barrio de Guayaquil, se convirtió en un atractivo turístico con participación directa de la población local incidiendo en la generación de ingresos y en el fortalecimiento del sentimiento de pertenencia (Cárdenas, 2014). En el nivel nacional, un programa como el de Pueblos Mágicos es una muestra de aprovechamiento de los recursos patrimoniales locales en términos de ingreso y uso de los bienes culturales locales (Sectur, 2012). En síntesis, el turismo se convierte en un buen instrumento para la recuperación y el mantenimiento del patrimonio artístico y cultural porque, al dotarlo de funciones productivas, lo incorpora a la cadena de valor y hace rentable su conservación (Crespi y Planells, 2003).

Para el caso del patrimonio religioso, celebraciones, ferias y festivales siguen teniendo una gran importancia, como lo demuestra su persistencia histórica en México, pero además han cobrado mucha relevancia en el marco del sector turístico. Con el paso del tiempo, estas celebraciones se han convertido en un atractivo. Se considera que un evento como este cumple una función turísticorecreativa, pero va más allá, es decir, no solo constituye una actividad de desplazamiento realizada por el ser humano entre dos puntos o comunidades, sino también un encuentro cultural en el cual confluyen o se reafirman los propios valores o visiones del mundo (reencontrarse con su cultura), en este caso, vinculado con lo religioso, así como un momento de descanso y entretenimiento: un periodo donde se despliegan valores consagrados en un espacio cargado de alta significación que pone una pausa a la vida cotidiana.

Los bienes culturales, sin embargo, no actúan en el vacío, sino que tienen una relación importante con su momento histórico y las condiciones socioeconómicas que definen sus aspectos axiológicos (Florescano, 1997; Bonfil, 1997). Al respecto, Thompson (2006) argumenta que una consecuencia de la contextualización de las formas simbólicas (rituales, creencias, prácticas, valores, 
bienes significativos y cualquier elemento significativo donde "cristaliza” la cultura) es que con frecuencia están sujetas a complejos procesos de valoración, evaluación y conflicto. Se pueden distinguir dos principales tipos de valoración:

- Valoración simbólica: proceso por medio del cual se les asigna un valor en virtud de las formas y la medida en que son estimadas por los individuos que las producen y las reciben; es decir, elogiadas o denunciadas, apreciadas o despreciadas por tales individuos.

- Valoración económica: proceso mediante el cual se asigna a las formas simbólicas un valor por el que podrían ser intercambiadas en un mercado. Por medio del proceso de valoración económica, las formas simbólicas se constituyen como mercancías a las que se les otorga un precio.

Ambos tipos de valoración se acompañan comúnmente de formas distintivas de conflicto. Los individuos que las producen y las reciben pueden asignar diferentes grados de valor simbólico a los bienes patrimoniales, de manera que un objeto elogiado por algunos puede ser denunciado o despreciado por otros. Lo anterior se puede describir como un conflicto de valoración simbólica. Tales conflictos ocurren siempre en un contexto social estructurado, es decir, caracterizado por asimetrías y diferencias socioeconómicas y culturales, ello explica las valoraciones simbólicas diferenciadas por el hecho de que los individuos se encuentran situados en distintas posiciones en la estructura social. Algunas evaluaciones tienen más peso que otras en función del individuo que las externa y la posición desde la cual lo hace, y algunos individuos están en una mejor posición que otros para externar sus evaluaciones, e incluso para imponerlas.

El proceso de valoración económica también se acompaña por lo general de conflictos. Los bienes simbólicos pueden ser valorados económicamente en diversos grados por diferentes individuos, en el sentido de que algunos de ellos pueden considerarlos más o menos valiosos de lo que otros los consideran; podemos describir esto como conflicto de evaluación económica (Thompson, 2006). Cabe señalar que el conflicto de valoración se refiere a la dimensión pública de los bienes culturales y no a la individual, es decir, una persona puede considerar invaluable un objeto por el hecho de que lo heredó de algún familiar, sin embargo, lo que interesa para el caso que analizamos tiene que ver con un consenso colectivo acerca de lo valioso que puede ser un bien teniendo en 
cuenta, además, aspectos vinculados con historia, antigüedad, material del que está elaborado, así como su asociación en términos de significación colectiva (identidad nacional, pertenencia a una comunidad).

El patrimonio, asimismo, puede contener otros tipos de valores. De acuerdo con Ballart (1996), se puede pensar en una categorización que da cuenta de las dimensiones trascendentes de los bienes culturales: un valor de uso (dimensión estrictamente utilitaria del objeto cultural: en el patrimonio religioso, tal valor responde a visibilizar o hacer tangible la "fe", las creencias o el misticismo de los creyentes), un valor formal (responde al hecho de que determinados objetos son apreciados por la atracción que despiertan en las personas, por su forma, su estética y las cualidades inherentes que presentan) y un valor simbólico (el cual conlleva un mensaje que hace que los sujetos se sientan parte de una comunidad). Esta tríada, aun en su simplicidad, da mucho juego en el asunto que nos ocupa, ya que admite incluir y categorizar varias de las posibilidades razonables de atribución de valor que los individuos acostumbran a otorgar a los objetos históricos y simbólicos. A continuación se describen los valores

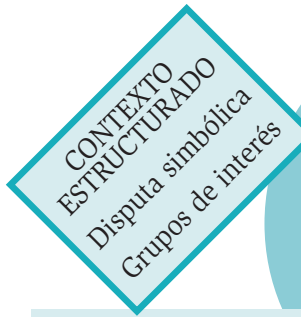

- Es importante desde la apreciación artística por el estilo, los materiales $\mathrm{u}$ otro elemento estético utilizado para realizarlo.

- El patrimonio religioso da cuenta de diferentes momentos históricos de la localidad.
VALORES DEL PATRIMONIO RELIGIOSO

Valor

Formal

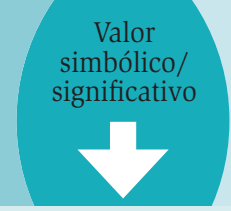

VALOR PREDOMINANTE.

- El patrimonio religioso en su sentido sacro representa la fe, creencias y cosmovisión de una colectividad, por lo que al visibilizarse algunas de sus formas (pinturas, esculturas, etc.), se puede reforzar una pertenencia y apropiación cultural.

- La apropiación y pertenencia se despliega entre otros aspectos, en diferentes celebraciones en honor de santos y/o vírgenes.
Valor de Uso

Fuente: Elaboración propia con base en Thompson 2016 y Ballart 1996. 
mencionados que constituyen un modelo para el análisis de los bienes patrimoniales (Ballart, 1996). La figura 1 sintetiza los elementos teóricos que fungen como base para explicar la problemática estudiada.

Este marco ayudará a explicar la forma en que los distintos grupos de interés, incluyendo a los turistas, construyen visiones diferenciadas, lo que incide en la apreciación y la apropiación del patrimonio, y en el manejo que se realiza de él -que oscila entre el proteccionismo y la mercantilización-, en un entorno de gestión conflictiva, porque los grupos de interés actúan sobre un contexto estructurado o de poder.

\section{Aproximación metodológica a la valoración del patrimonio religioso con fin turístico}

La investigación sobre la valoración y el uso del patrimonio religioso en la ciudad de Toluca, México, tuvo como base el método etnográfico. De acuerdo con varios autores (Martínez, 2005; Guber, 2001; entre otros), la etnografía es un tipo de descripción/interpretación, implica elaborar una representación coherente de lo que piensan y dicen los "nativos", de modo que esa "descripción" no es ni el mundo de los nativos, ni cómo es el mundo para ellos, sino una conclusión interpretativa que elabora el investigador.

En el caso del presente análisis, además, lo que interesa es derivar esa interpretación a partir de la visión de los sujetos que constituyen grupos de interés en relación con el manejo de los bienes religiosos, entre otros, se incluye tanto a actores religiosos como gubernamentales, así como de la iniciativa privada. Ellos representarían, en el lenguaje antropológico, la visión emic de la gestión patrimonial en un marco de aprovechamiento turístico como campo simbólico en disputa (Thompson, 2006).

Coherente con la definición de la etnografía como método que integra diversas técnicas, se realizaron entrevistas semiestructuradas dirigidas a autoridades de los sectores turístico y religioso, la iniciativa privada, y de una asociación civil, lo cual permitió un acercamiento a valoraciones, usos, problemáticas y expectativas de los distintos grupos de interés, así como a información para su aprovechamiento turístico. Se llevó a cabo, también, observación directa en lugares donde se desarrollaron festividades religiosas, lo que permitió la 
identificación, el registro y la evaluación de los bienes religiosos patrimoniales; igualmente, se aplicaron encuestas que hicieron posible obtener un perfil socioeconómico de los visitantes.

Para el caso de las encuestas (100 en cada uno de los eventos religiosos analizados), se efectuaron en diferentes fechas durante 2016: en las festividades a la Virgen del Carmen (16 julio) y a Nuestra Señora de la Merced (24 de septiembre). Es importante mencionar que las encuestas se aplicaron en tales festividades porque ambas forman parte del recorrido turístico denominado Ruta de la Fe. Aparte, la ciudad de Toluca tiene otras festividades religiosas en diferentes meses del año; por ejemplo, durante la Semana Santa, se eslabonan diversos templos e iglesias que conforman una ruta solemne para recordar la muerte de Cristo, donde destaca un vía crucis viviente en el cual participan cientos de personas que llevan consigo enormes figuras religiosas de cada una de las cofradías.

En este contexto, es relevante reconocer el papel del visitante, puesto que en torno a este se diseñan estrategias turísticas que inciden directamente en la gestión del patrimonio religioso de la localidad; además, el conocimiento de ese perfil muestra, de manera particular, la existencia de un interés específico sobre tales bienes.

\section{Turismo religioso en el centro histórico de la ciudad de Toluca, México}

Toluca de Lerdo es la capital del Estado de México, cuenta con una población de 819561 habitantes y es el centro de la quinta zona metropolitana más habitada del país, con una población estimada en 2010 de 1846602 habitantes. Toluca se encuentra a solo $66 \mathrm{~km}$ de distancia de la Ciudad de México (Ayuntamiento de Toluca, 2013).

Si bien el municipio de Toluca no puede ser considerado un territorio netamente turístico, concentra en su centro histórico un sinnúmero de parques, monumentos históricos y arquitectónicos que conforman su patrimonio natural, cultural e histórico, y fungen como puntos de atracción. A su vez, el municipio cuenta con una gama de ferias, festivales y algunas tradiciones que brindan identidad a los habitantes de la capital mexiquense, y los cuales, como bien se 
conoce, pueden llegar a ser estimados como recursos culturales capaces de generar desplazamientos con interés turístico.

Aunado a esto, Toluca tiene atractivos para captar visitantes nacionales e internacionales, como el Cosmovitral-Jardín Botánico, el volcán Nevado de Toluca, los Portales y la zona arqueológica de Calixtlahuaca, así como infraestructura para realizar diferentes actividades culturales y artísticas.

En lo que respecta al patrimonio religioso, cuenta con edificaciones que datan de los siglos XVI, XVII y XVIII, las cuales se han ido incorporando a la oferta turística de la localidad, pues desde 2014 se puso en marcha la denominada Ruta de la Fe, con el propósito de difundir el patrimonio religioso de la ciudad (Ayuntamiento de Toluca, 2014). De igual manera, participa en esta estrategia la iniciativa privada al implementar el Tranvía Turístico, el cual brinda un recorrido por el centro histórico haciendo mención y promoción del patrimonio religioso de la ciudad. Estas acciones permiten visualizar un interés específico en relación con el uso y aprovechamiento de los bienes culturales, así como todo un tejido que involucra a más actores o grupos de interés, de los cuales existe poca información que dé cuenta de la forma en que se articulan con el patrimonio religioso.

Los grupos de interés identificados que se articulan en torno al patrimonio religioso en la ciudad son el Instituto Municipal de Cultura (IMC), la Dirección de Turismo y Artesanías, el INAH, el Patronato Pro Centro Histórico (asociación civil), el Tranvía Turístico Toluca (iniciativa privada), la Diócesis de Toluca (jerarquía eclesiástica encargada de cada iglesia/parroquia) y las cofradías (parte de la comunidad local que se interesa por la organización de las festividades religiosas en honor a algún santo o virgen).

Si bien existen diversos problemas vinculados con la gestión del patrimonio religioso en el sentido mencionado líneas arriba (es decir, como una actuación orientada a optimizar tales bienes y recursos para obtener una ganancia en términos de "rentabilidad social y económica" y, al mismo tiempo, con la posibilidad de considerar los intereses de los distintos grupos involucrados), entre los que se encuentran la falta de información o del registro de esos bienes o de las condiciones físicas en que se hallan, algo que resulta clave tiene que ver con el hecho de que los grupos de interés no cuentan con una red de relaciones, la que resulta necesaria para el logro de un fin común (rentabilidad social y eco- 
nómica), lo cual explica que se realicen acciones pero con objetivos diferentes. Esta falta de comunicación y de interacción de los grupos plantea dificultades para el aprovechamiento del patrimonio religioso con fines turísticos.

Para el caso de los grupos de interés turístico -y esto es esencial para la consecución de una gestión eficaz-, si bien se encuentran relacionadas autoridades gubernamentales, religiosas, iniciativa privada, asociaciones civiles y población local, por otra parte existe poca vinculación transversal, lo que ha traído consigo que cada grupo lleve a cabo estrategias que le permiten conseguir las metas particulares, pero escasamente acciones integrales. En el cuadro 1 se explicita el tipo de intervención o fin de los distintos grupos de interés identificados.

\section{CUADRO 1. Grupos de interés y tipos de intervención}

Grupo de interés

Tipo de intervención

Instituto Nacional de Antropología e Historia (INAH), Instituto Municipal de Cultura (IMC), Dirección de Turismo, Patronato Pro Centro Histórico, Diócesis

Diócesis, cofradías

Conservación/Protección del patrimonio religioso

Eventos que acercan a los asistentes con su religión (incrementar la fe)

IMC, Dirección de Turismo, Patronato, Tranvía

Difusión/Rentabilidad del patrimonio

IMC , Dirección de Turismo, Diócesis, cofradías

Promoción/difusión religiosa (eventos de Semana Santa en el centro de la ciudad)

Turistas

Disfrute/apreciación del patrimonio religioso

Fuente: Elaboración propia.

Además de la conservación del patrimonio, que podría considerarse una plataforma común entre los grupos de interés (pero cada uno desde su enfoque), pareciera que hay pocas zonas en donde coinciden directamente, por lo que el uso y manejo del patrimonio religioso no se encamina a un solo objetivo y, menos aún, al aprovechamiento turístico, ya que solo el IMC, la Dirección de 
Turismo y el Tranvía Turístico cuentan con un incipiente deseo de gestionarlo bajo este fin. Por otra parte, aunque se realizan constantemente festivales, exposiciones, ferias, etcétera, que de una u otra forma dan cuenta del uso del patrimonio religioso en Toluca, casi nunca se tiene información de cómo se incorpora a la oferta turística de la ciudad. Esto es: queda claro que los distintos grupos de interés participan en la apropiación del patrimonio incluyendo a la comunidad local, sin embargo, poco se sabe acerca de lo que hacen o dejan de hacer en la búsqueda del fortalecimiento o la viabilidad de un turismo religioso.

El patrimonio religioso, entonces, se puede decir que es visible para las personas, pero lo que aparece un tanto difuso es la forma de gestión de tales bienes predominando, hasta el momento, el interés de grupo o corporativo. En este sentido, el turismo podría convertirse quizá en ese eje transversal que articule las diversas dimensiones del patrimonio desde la lógica de una gestión más allá de la tradicional visión de la rentabilidad económica.

La temática es relevante debido a que en el centro histórico de la ciudad de Toluca se concentran conjuntos arquitectónicos religiosos (templos, iglesias) que albergan en su interior diferentes objetos patrimoniales valiosos (Ayuntamiento de Toluca, 2013), entre los que destacan el antiguo convento de los frailes carmelitas, el santuario de La Merced, la catedral erigida en honor a San José y el templo de Santa María de Guadalupe, los cuales tienen características que mantienen su capacidad de referentes identitarios para la comunidad local, pero que podrían usarse e incorporarse dentro de la oferta turística. Cabe señalar que, en 2014, las autoridades gubernamentales tomaron la decisión de implementar la Ruta de la Fe como atractivo turístico, no obstante, hace falta dar cuenta de distintos aspectos que fortalezcan la viabilidad del patrimonio religioso de la ciudad como recurso de desarrollo (rentabilidad económica) y bien cultural (rentabilidad social), a través de lo que hacen, desean y consideran los grupos de interés como elemento clave de la gestión del patrimonio. Por ello, resulta pertinente conocer, entre otros aspectos, qué valoran del patrimonio, cómo lo usan, cuál es el principal interés respecto a los bienes culturales y de qué forma se integra el patrimonio al mercado turístico. 


\section{Valoración del patrimonio religioso en Toluca}

Si bien en Toluca existe información sobre el patrimonio religioso (concretamente arquitectura) y las festividades religiosas, esta es fragmentada, dispersa y específica. Hasta el momento no hay un estudio enfocado a analizar su influencia sociocultural y turística a pesar de que, en diversas festividades, participan cientos de personas locales, de los municipios cercanos y turistas de diferentes estados.

En el cuadro 2 se muestra una panorámica de las principales celebraciones religiosas en el centro histórico de la ciudad, y destaca el hecho de que, aun cuando no cubren el año completo, varias de ellas se planean con mucha anticipación, generando la participación de la comunidad local, aporte al vínculo social muy poco estudiado. Por otra parte, también queda claro que un problema para el caso del desarrollo turístico es la estacionalidad de las fiestas, que no permite una afluencia de visitantes más regular.

CuAdRo 2. Calendario de festividades religiosas en la ciudad de Toluca, México

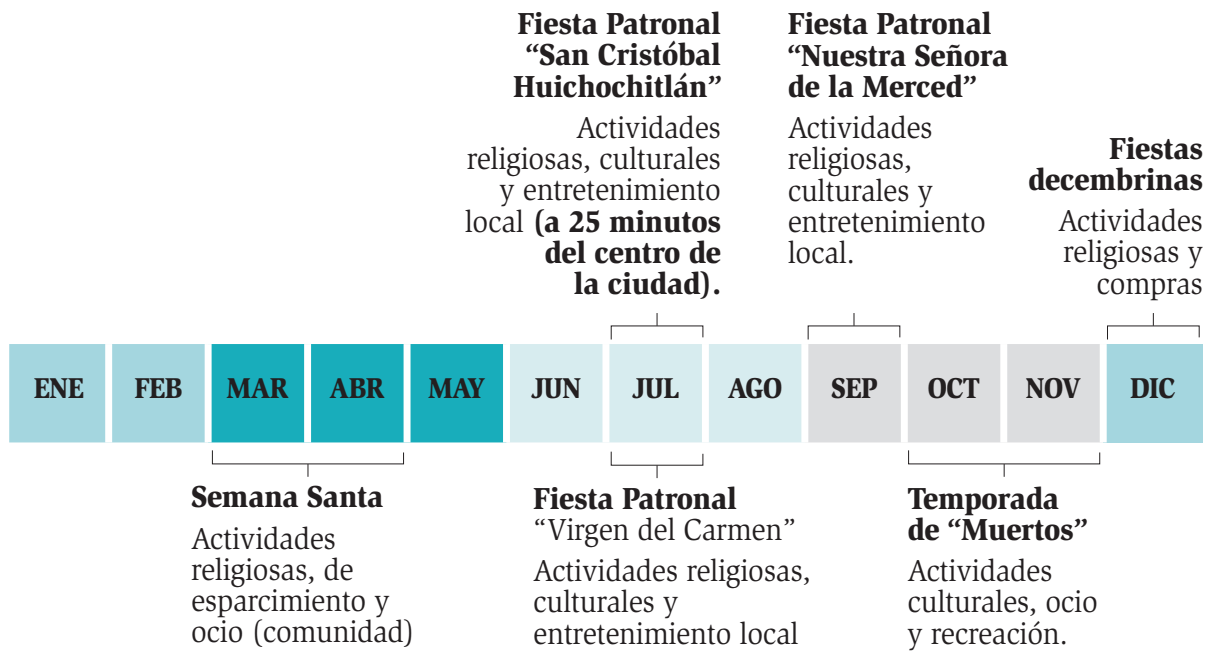

Fuente: Elaboración propia con base en trabajo de campo, 2016 
Por otro lado, es relevante mencionar que existen otras festividades religiosas susceptibles de ser incluidas en la oferta turística de la localidad, pero dada la distancia a la que se encuentran del primer cuadro de la ciudad los lugares donde se llevan a cabo no es posible que se integren a las rutas ya establecidas, como la celebración desde hace más de 300 años de la Virgen del Carmen y Nuestra Señora de la Merced (Sánchez, 2013).

Los visitantes: ¿quiénes son, qué aprecian del patrimonio religioso, cómo lo valoran?

El cúmulo de templos, iglesias y festividades religiosas en Toluca es concurrido por cientos de personas anualmente, de las cuales poco se sabe en términos de su perfil y sus razones para aproximarse a tales bienes. Estos visitantes son uno de los principales grupos de interés, y, aunque en la literatura sobre el tema del turismo cultural se delinean como turistas de nivel socioeconómico D o $\mathrm{D}+$, no existen mayores datos que permitan la identificación de los que están propiamente interesados en el patrimonio religioso, por esta razón, se intentó caracterizar a quienes asisten a las celebraciones religiosas o tienen interés en el patrimonio religioso de Toluca por medio de una encuesta.

De acuerdo con los resultados arrojados, quienes acuden a las festividades religiosas y tienen algún interés en este patrimonio son, principalmente, adultos jóvenes (de 25 a 35 años y de 36 a 45 años), que asisten en pareja, provienen de los municipios vecinos (Zinacantepec, Metepec, Almoloya de Juárez, San Mateo Atenco, Lerma, entre otros) y, en menor medida, de las entidades circunvecinas (Ciudad de México, Puebla, Aguascalientes, Guerrero). Es decir, son los pobladores de la zona metropolitana de Toluca quienes acuden a presenciar las actividades religiosas que se desarrollan en el centro histórico de la ciudad. También se encontró que quienes acuden a tales celebraciones combinan su asistencia con algunas otras actividades tales como visita a familiares, compras en el centro de la ciudad y diversión o placer (ocio) en los diferentes espacios de Toluca.

Respecto a los gastos, es notable que no realizan una derrama significativa, ya que la mayoría declaró que gasta en promedio 500 pesos, lo cual se dispersa en distintos rubros: transporte (una gran parte utiliza transporte público y algunos otros vehículos particulares, lo que hace que desembolsen en combustible); 
alimentación (en puestos callejeros que se colocan durante las celebraciones y, en menor proporción, en restaurantes de fast food). Finalmente, algunos más adquieren productos acordes con la ocasión (el tradicional pan de fiesta o artículos religiosos, por ejemplo).

Resulta relevante el hecho de que no solo visitan los espacios religiosos, sino que también van a algunos otros lugares culturales como museos, plazas públicas, parques y, por supuesto, los templos católicos que incluye la Ruta de la Fe, la cual consideran complementaria a su visita. Según los hallazgos realizados, los visitantes no acuden a disfrutar del patrimonio religioso por su valoración primordial, es decir, por su sentido meramente sacro, sino por su sentido estético, su relevancia artístico-histórica. La valoración simbólica permite conocer que la religión que profesan los asistentes a tales lugares los motiva de alguna forma a conocer los templos y sus imágenes u objetos sacros. La valoración menos importante es la económica, o sea, los visitantes no dimensionan los usos económicos que el patrimonio religioso pudiera generar no solamente para su propio cuidado y preservación, sino también para la población local dueña de él.

\section{Anfitriones: intereses fragmentados}

Como se mencionó en el cuadro 1, existen diversos grupos de interés que tienen valoraciones distintas sobre el patrimonio religioso, las cuales se pueden delinear con base en los modelos de Ballart y Thompson. Esto significa que alrededor del patrimonio se aprecian visiones que van desde la postura conservadora (el patrimonio es sagrado y depositario de la identidad, por lo que hay que mantenerlo y resguardarlo) hasta la más funcional (el patrimonio se puede usar para generar ingresos y desarrollo). En términos de la gestión del patrimonio, ello implica posiciones que se orientan a la rentabilidad social (valoración más conservadora) hasta la rentabilidad económica (valoración funcional), determinando con ello buena parte de las acciones que llevan a cabo los diferentes grupos de interés. A continuación, y considerando como trasfondo lo señalado, se describen los aspectos vinculados con la gestión del patrimonio religioso según los principales grupos de interés locales. 
Conflictos de valoración y uso del patrimonio religioso con fines turísticos en el centro

\section{AUTORIDADES GUBERNAMENTALES}

En este grupo de interés hay dos instituciones principales: la Sectur y la Secretaría de Cultura. Aunque cada una de ellas tiene una visión contrastante en relación con los bienes patrimoniales (la primera orientada básicamente a la rentabilidad económica y la segunda a la rentabilidad social), se puede decir que, en ambos casos, se caracterizan por una gestión centralizada, lo cual impide una colaboración estrecha entre ambas a pesar de tener un bien cultural común: el patrimonio religioso. Esa división explica el hecho de que no sumen esfuerzos en la conservación, la difusión y el aprovechamiento de los bienes culturales, cuya consecuencia es un avance lento en la gestión del patrimonio religioso de la ciudad con fines turísticos. Se implementa una diversa gama de actividades por parte de las dos instancias para alentar al turismo en la ciudad, solo que mediante diferentes estrategias: algunas de ellas estrechamente vinculadas con la religión (recorrido turístico guiado por capillas e iglesias, por ejemplo), y otras que son complementarias, entre las que destacan conciertos de bandas y grupos locales, obras de teatro, exposiciones artísticas, talleres de alfarería, modelado de dulce de alfeñique, cartonería (para la elaboración de los "Judas", que son imágenes que representan a los demonios y a personajes públicos y populares que se han visto envueltos en escándalos políticos o sociales).

Respecto al sector turismo, como ya se mencionó, las autoridades gubernamentales de la localidad tomaron la decisión de crear una ruta turística denominada Ruta de la Fe, la cual tiene como meta que los visitantes conozcan los diferentes templos católicos que se encuentran en el primer cuadro de la ciudad y que alberga edificaciones que datan del siglo xvI. Esa ruta enfatiza la arquitectura religiosa, relegando aquellos bienes muebles albergados en las edificaciones. Los recorridos guiados han ido sufriendo modificaciones debido a la demanda que se ha dado en la localidad. En temporada de fiestas religiosas, tales recorridos aumentan en número de salidas y de personas que los realizan, puesto que el mercado potencial son visitantes, y pasa a un segundo plano la población que de igual manera tiene inclinación en tomar los tours (lo que reafirma el compromiso de la Sectur por incrementar la cantidad de visitantes que se traducirá en gasto turístico). 
En cuanto a las autoridades del sector cultural, estas han implementado proyectos de apoyo hacia artistas locales, lo cual se ha traducido en una agenda cultural que en ocasiones complementa la oferta turística de la localidad, no obstante, esos espectáculos tienen como finalidad el acercamiento de la población con expresiones culturales locales (es relevante mencionar que el objetivo de tal institución es preservar y difundir la cultura local). Lo anterior demuestra que si bien las estrategias implementadas por ambas instituciones públicas están acordes con sus funciones, no parecen complementarse del todo, lo que resulta confuso, puesto que las dos toman como parte de sus estrategias el patrimonio religioso de la ciudad, pero una como punto de atracción turístico y otra como espacio de expresión cultural.

\section{AUTORIDADES RELIGIOSAS Y COFRADÍAS}

Los sacerdotes de los templos que se encuentran en el centro histórico de la localidad (Diócesis de Toluca), así como las pequeñas asociaciones integradas por la comunidad devota de un santo o virgen en específico, son quienes se encargan de organizar las ya tradicionales ferias (juegos mecánicos, danzas, misas solemnes, etc.), las cuales, con autorización y guía de cada párroco, se llevan a cabo con el fin de incrementar la fe entre los asistentes y acercarlos con sus creencias. Aunque estas festividades se realizan para la población local, no resulta extraño encontrarse con algunos visitantes de otras localidades, quienes, atraídos por la singularidad de las celebraciones religiosas, asisten a ellas y disfrutan de las actividades programadas.

En el caso de los sacerdotes que se encuentran al frente de los templos religiosos del centro de la ciudad, es interesante la forma en que se apropian de ese patrimonio, puesto que no lo toman como sus responsables (debido a que, al ser considerado patrimonio de la localidad, entonces le pertenece al Estado). Los sacerdotes asumen como parte de su control el horario de apertura y cierre de estos espacios públicos, y, si bien se entiende el carácter sacro que representan, resulta extraña la manera en que se definen horarios de actividades tanto religiosas como culturales. Aunque la actividad religiosa no tiene como objetivo crear estrategias turísticas, los sacerdotes están conscientes de su relevancia al comenzar a fijar horarios de visita específicos con el propósito de que los visitantes puedan realizar un recorrido por el interior de los templos. Incluso 
en la Catedral de Toluca se cuenta con un pequeño espacio con mamparas que contienen información importante para el turista (estilo arquitectónico, historia del lugar, semblanza de festividades religiosas, entre otra). Las actividades implementadas denotan el valor simbólico que el patrimonio representa, relegando a último fin la función turística. Esta actividad se visualiza como circunstancial, aceptando la visita de turistas, pero sin ofrecerles algún tipo de servicio especial. No han puesto en marcha estrategias que incorporen al turismo como una oportunidad de fomentar las creencias religiosas, ya que solo se limitan a actividades espirituales o de caridad.

En cuanto a las cofradías, creadas a partir de la comunidad religiosa, y al considerarse una extensión de la actividad sacerdotal, solo se encargan de actividades operativas respecto a la organización de las festividades religiosas, puesto que las decisiones finales son tomadas precisamente por los sacerdotes de cada templo. Las cofradías son las responsables de realizar presupuestos, contactar a artistas locales para presentaciones en las festividades y conseguir permisos para cerrar o utilizar espacios públicos.

\section{SECTOR PRIVADO}

El Tranvía Turístico surge en 2009 en Toluca con la finalidad de realizar recorridos turísticos por su centro histórico. El recorrido inicia en la Catedral y funciona viernes, sábados, domingos y días festivos. Existe un módulo donde se compran los boletos y cada hora, a partir de las 11:00 y hasta las 18:00, se puede tomar el recorrido. Cuenta con diferentes rutas, las cuales van cambiando y adaptándose temáticamente según las festividades de la localidad: Leyendas de Toluca, los fines de semana (temporada de muertos), leyendas decembrinas (fiestas navideñas) y recorridos sociales (graduaciones, bodas, XV Años).

Tal iniciativa, al paso de los años, ha ido creando pequeñas colaboraciones entre diversos grupos involucrados en la actividad turística de la localidad (asociación civil y autoridades religiosas), lo cual se ha visto reflejado en el contenido de las mencionadas rutas que se ofertan. La información que se difunde y promueve durante los recorridos se basa en arquitectura histórica, artística y religiosa de la localidad, así como en escenificaciones de leyendas con la participación de un grupo de actores, que representa y armoniza los trayectos entre 
los diferentes puntos. Aunque tal emprendimiento ha comenzado con una gestión incluyente por los distintos grupos involucrados, aún no logran concretar algún vínculo con las autoridades turísticas municipales, puesto que los fines entre ambos grupos suelen contraponerse al buscarse rentabilidad social (por parte de las autoridades gubernamentales) y rentabilidad económica (por parte del Tranvía Turístico). Esto se visualiza en estrategias similares implementadas entre ambos grupos (ya que tanto las autoridades gubernamentales como la iniciativa privada cuentan con recorridos que toman como puntos de atracción el patrimonio religioso: el gobierno con su denominada Ruta de la Fe y la iniciativa privada con su recorrido del centro histórico), pero poco fructífero para ambos.

Lo anterior denota una serie de discrepancias con la que se enfrentan ambos grupos y que da cuenta del conflicto de valoración de los diferentes bienes patrimoniales religiosos. En las entrevistas realizadas con informantes clave involucrados en el negocio del tranvía, se ha notado cierta tendencia a buscar colaboraciones con algunos otros grupos en el manejo y uso del patrimonio religioso, lo que deja latente la posibilidad de un trabajo colaborativo por parte de los diversos grupos y donde, justamente, el turismo sea el eje transversal que permita converger en una misma meta los objetivos de los distintos grupos encargados. En la figura 2 se muestran las diferentes valoraciones del patrimonio religioso por parte de los grupos de interés, lo cual explica mucho de lo analizado en los apartados anteriores. Los tres colores representan los valores enmarcados en el modelo de Ballart (valor de uso, valor formal y valor simbólico). En la parte inferior se encuentran los principales grupos de interés que usan, se apropian y manejan el patrimonio religioso de la ciudad de Toluca. Del lado izquierdo aparece la escala utilizada para determinar el valor que estos grupos le otorgan al patrimonio religioso de acuerdo con la información recabada. Esta escala considera tres valores en orden ascendente: "poco importante", "importante" y "muy importante". En el caso de las instituciones públicas como el INAH, resaltan los valores simbólicos, es decir, se ve al patrimonio religioso como un elemento donde radica la identidad cultural, de manera que muchos de sus esfuerzo se quedan en un nivel de protección y conservación (enfoque proteccionista); esto puede explicar que existan pocas iniciativas promovidas por el Instituto orientadas al uso en términos de aprovechamiento turístico, además de que los objetivos institucionales no lo consideran. 


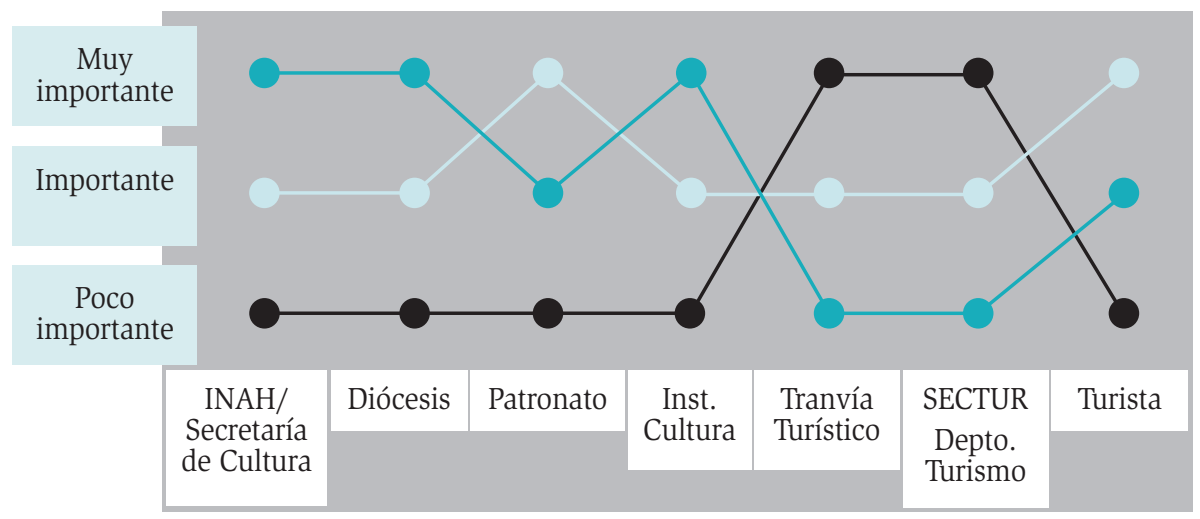

Valores asociados a los bienes patrimoniales
Valor simbólico
Valor formal artístico-estético
Valor de uso económico

Contexto

Fuente: Elaboración propia.

GRÁFICO 2. Valoración de formas simbólicas por grupos de interés involucrados

En cambio, la Sectur, que también es una institución pública, tiene una valoración más utilitaria de los bienes, de modo que se puede enmarcar en el enfoque economicista (búsqueda de la rentabilidad), lo cual se confirma por la existencia de pocas experiencias en las cuales el beneficio turístico incorpore a la comunidad local. En el mejor de los casos, se irradia cierto beneficio particular a los habitantes directamente articulados al mercado turístico local (Robles, 2001; Romo, 2004; Velasco, 2009). Por el contrario, es frecuente encontrar denuncias de los impactos negativos del turismo en términos de cambio de tradiciones, agotamiento de los recursos culturales y naturales, y polarización socioeconómica (Rosas, 2003; Prats, 2005; Machuca, 2005; Muñoz, 2011).

Es evidente que el conflicto de valoración, recuperando a Thompson, se presenta entre los diferentes grupos de interesados en el patrimonio, pues cada uno construye un discurso significativo desde una posición estructurada que impide una colaboración o meta en común. O sea, se pone en evidencia la nula comunicación que existe entre los diversos actores, prevaleciendo acciones 
competitivas y no colaborativas. Por ejemplo, en las festividades, cada uno de los grupos realiza eventos de forma simultánea en espacios dirigidos a públicos distintos, de forma que la comunidad y los visitantes se conflictúan al tener que tomar decisiones sobre con quién, en dónde y cuándo asistir a esos eventos, la mayoría con objetivos diferentes: algunos meramente religiosos, otros de esparcimiento (talleres), o bien, de recreación (conciertos, ferias, etc.). Sería importante que los grupos de interés comenzaran a trabajar en alianzas que les permitieran avanzar y alcanzar tales metas, como se demuestra en el caso del Tranvía Turístico (sector privado), que, al implementar sus recorridos guiados y contar con el apoyo y la colaboración de algunas autoridades religiosas y de asociaciones civiles, ha perdurado por alrededor de ocho años y ha incrementado su oferta turística con el paso del tiempo. No obstante, la realidad de estos grupos enfrenta la continua lucha de poder entre las autoridades religiosas y las gubernamentales que, por cuestiones oficiales, en ambas, limita el trabajo de manera coordinada y conjunta en cuanto a proyectos se trata. Tal colaboración no solamente beneficiaría en términos económicos a los involucrados, sino que, a su vez, el patrimonio religioso en cuestión contaría con recursos que podrían ser utilizados para su conservación, restauración, investigación, difusión o algún otro aspecto que se considere necesario; se trabajaría, entonces, en la búsqueda de la rentabilidad social y económica, sin soslayar el significado comunitario que representa el patrimonio religioso.

\section{Conclusiones}

El patrimonio cultural constituye una clase de bienes que, desde la lectura moderna, merecen ser conservados, protegidos, difundidos y transmitidos, puesto que no se trata solo de piedras, edificios, monumentos o tradiciones singulares, también condensan pertenencia, identidades y valores (Torija, 2015). En la actualidad y derivado de los diferentes conflictos bélicos o sociales que existen en el mundo, una gran gama de bienes culturales -y en especial religiosos- son destruidos, lo que trae consigo que toda la carga simbólica y de significados o saberes que emanaban de tales patrimonios se extinga y que una parte de la historia y de la identidad de las comunidades se pierda irremediablemente (Unesco, 2003). Tal es el caso del patrimonio cultural e histórico de Siria, que 
ha sufrido las consecuencias de cinco años de guerra y de la barbarie del Estado islámico. Además de las guerras, existe otro tipo de acciones, como los actos vandálicos, que se encuentran presentes también en México, donde ya se ha llegado al extremo de destruir bienes catalogados como históricos y protegidos por la legislación correspondiente, por ejemplo la capilla del Santo Cristo de San Pablo del Monte, Tlaxcala (Pérez, 2015). Asimismo, son recurrentes las noticias acerca del saqueo de objetos artístico-religiosos de los cientos de templos propagados por todo el territorio nacional, los cuales son vendidos en el "mercado negro". El patrimonio religioso, en sus diferentes modalidades (pinturas, retablos, imágenes, etc.), data de cientos de años atrás, lo que aumenta su valor económico y el deseo de los coleccionistas por adquirirlos a cualquier costo.

El trabajo colaborativo de los grupos de interés en el manejo y uso del patrimonio religioso traería consigo una serie de beneficios que puede incluir no solo lo relativo a la protección y la conservación, sino también los vinculados con los aspectos más utilitarios, como puede ser la rentabilidad económica, o los más trascendentales, como el fortalecimiento de la identidad cultural de un grupo social. En el caso de la presente investigación, se ha mostrado al turismo cultural como un área de oportunidad, ya que una gestión adecuada y conjunta de los bienes patrimoniales puede traer consigo tanto beneficios económicos (ingresos) como sociales (apropiación por parte de la comunidad). Sin embargo, el turismo en México y en el nivel internacional se ha caracterizado por mantener una visión utilitaria del patrimonio (por lo menos es lo que se puede decir del sector público, encarnado en las secretarías de Turismo federal y estatal), en la cual se busca sobre todo una rentabilidad económica. Esto es particularmente delicado cuando los bienes culturales se incorporan a un mercado turístico, porque no constituyen cualquier clase de mercancía, en la medida en que cristalizan aspectos y valores identitarios de una comunidad. El patrimonio religioso, además, resulta más delicado en tanto encarna atributos sacros.

Los resultados arrojados dan cuenta, de manera general, de cómo se está usando el patrimonio religioso en una ciudad que no tiene tradición turística religiosa, pero cuyo caso permite plantear algunos aspectos problemáticos acerca de la forma en que se valoran determinados bienes culturales de acuerdo con los grupos sociales que los usan y aprovechan. Esto no puede explicarse sin considerar las posiciones estructuradas en que se encuentran tales grupos y que 
nos permite delinear las características de su apropiación, acciones e intereses en torno al patrimonio. De forma global, es interesante anotar que:

- El aprovechamiento del patrimonio religioso de Toluca todavía se encuentra en un estado incipiente de uso turístico. Se puede decir también que existe un área de oportunidad en la medida en que la ciudad cuenta con patrimonio tangible e intangible que puede ser atractivo para el visitante, lo cual explica el interés, por parte de algunos grupos, por incorporar y ofrecer nuevos usos.

- Los grupos de interés identificados y encargados de la gestión del patrimonio religioso trabajan bajo acciones específicas, a lo cual se ha denominado gestión diferenciada, lo que imposibilita estrategias de colaboración exitosas en el nivel local o regional, puesto que se realizan con recursos limitados y de interés corporativo.

- Los usos, la valoración y la apropiación del patrimonio religioso son diferentes en cada grupo de interés identificado, por lo que resulta necesario conocerlos para hacerlos converger bajo una misma meta, de manera que se puedan construir colaboraciones y estrategias transversales que tengan como base o que incluyan la actividad turística como eje de desarrollo y estrategia de conservación patrimonial.

- Hasta el momento no se aprecia una instancia que logre articular las diversas dimensiones del patrimonio desde la lógica de una gestión más allá de la tradicional visión de la rentabilidad económica. El turismo puede ser un campo propicio para una gestión del patrimonio con contenido social, pero es necesario reorientar la valoración economicista que caracteriza a las administraciones actuales. Es preciso tender puentes con las instancias responsables de la cultura y crear acciones transversales orientadas a lo que llamamos rentabilidad social que implica beneficios para la comunidad local y no solo para un grupo de interés.

- El estudio de las formas de valoración, apropiación y uso del patrimonio religioso en la ciudad de Toluca muestra los obstáculos a los que se enfrentan los grupos de poder identificados para el logro de una gestión integral, así como sus limitaciones y alcances en las estrategias implementadas por cada uno de ellos. 


\section{Fuentes consultadas}

Andrade, M. (2009). Análisis del templo de la Inmaculada Concepción ubicado en Ozumba, Estado de México como recurso cultural turístico (Tesis de licenciatura en Turismo). Universidad Autónoma del Estado de México, Facultad de Turismo y Gastronomía, Toluca, México.

Ayuntamiento de Toluca. (2013). Guía turística y artesanal de Toluca. Toluca: Autor. Recuperado de http://www.toluca.gob.mx/gu\%C3\% ADatur \% C3\% ADstica-y-artesanal

Ayuntamiento de Toluca. (2014). Ruta de la Fe, nuevo recorrido en Turibús para visitantes de Semana Santa en Toluca. Toluca: Autor. Recuperado de http://www.toluca.gob.mx/ruta-de-la-fe-nuevo-recorrido-enturib \% C3 \% BAs-para-visitantes-de-semana-santa-en-toluca

Ballart, J. (coord.). (1996). El valor del patrimonio histórico. Madrid: Universidad Complutense. Recuperado de http://revistas.ucm.es/index. php/CMPL/article/download/CMPL9696330215A/29835JOSEP

Bermúdez, A., Arbeloa, J. V. M. y Giralt, A. (2004). Intervención en el patrimonio cultural. Creación y gestión de proyectos. Madrid: Síntesis.

Bonfil, G. (1997). Nuestro patrimonio cultural: un laberinto de significados. En E. Florescano (coord.), El patrimonio nacional de México (pp. 28-56). México: Fondo de Cultura Económica/Consejo Nacional para la Cultura y las Artes.

Cámara de Diputados. (19 de marzo de 2016). El turismo religioso mueve anualmente casi 30 millones de personas en México. Boletín, 1174. Recuperado de http://www5.diputados.gob.mx/index.php/esl/ Comunicacion/Boletines/2016/Marzo/19/1174-El-turismoreligioso-mueve-anualmente-casi-30-millones-de-personas-enMexico-Andres-Fernandez

Cárdenas, F. (2014). El turismo como eje de la intervención del Cerro y su escalinata. En Las relaciones de vecindad y la regeneración urbana en Guayaquil. Caso: Cerro Santa Ana (Tesis de maestría). Universidad Andina Simón Bolívar, Guayaquil, Ecuador.

Chavolla, J. (2014). Reconciliando el patrimonio cultural religioso y cívico en Jiquilpan, México. Culturales, 2(2). Recuperado de http://www. scielo.org.mx/scielo.php?script = sci_arttext\&pid $=$ S1870- 


\section{$11912014000200004 \&$ lang $=p t$}

Crespi, M. y Planells, M. (2003). Patrimonio cultural. Madrid: Síntesis.

Elbez, M. (2017). ¿Quién es maya en un entorno turístico? Patrimonialización y cosmopolitización de la identidad maya en Tulum, Quintana Roo, México. Cultura y Representaciones Sociales, 11(22). Recuperado de http:// www.scielo.org.mx/scielo.php?script $=$ sci_arttext\&pid $=$ S2007$81102017000100034 \&$ lang $=p t$

Fernández, A. (2012). La Virgen de Talpa: religiosidad, turismo y sociedad. Política y Cultura, 38. Recuperado de http://www.scielo.org. $\mathrm{mx} /$ scielo.php? script $=$ sci_arttext\&pid $=$ S0188$77422012000200003 \&$ lang $=\mathrm{pt}$

Florescano, E. (1997). El patrimonio nacional. Valores, usos, estudio y difusión. En E. Florescano (coord.), El patrimonio nacional de México (pp. 15-27). México: Fondo de Cultura Económica/Consejo Nacional para la Cultura y las Artes.

Gamboa, M. (2016). Turismo místico y turismo religioso. Las diferencias conceptuales desde una mirada antropológica de la subjetividad. Revista Uruguaya de Antropología y Etnografía, 1(1). Recuperado de http:// www.scielo.edu.uy/scielo.php?script = sci_arttext\&pid = S239368862016000100004\&lang $=\mathrm{pt}$

Guber, R. (2001). La etnografía: método, campo y reflexividad. Bogotá: Grupo Editorial Norma.

López, A. (2015). El turismo cultural: un aporte a la inclusión social. México: Consejo Nacional para la Cultura y las Artes. Recuperado de http://politicasculturales.com.mx/turismo-cultural.html

Machuca, J. (2005). Reflexiones en torno a la salvaguardia del patrimonio cultural inmaterial. En Patrimonio cultural oral e inmaterial. La discusión está abierta. Antología de textos (Patrimonio Cultural y Turismo. Cuadernos 9) (pp. 73-93). México: Consejo Nacional para la Cultura y las Artes. Recuperado de http://www.conaculta.gob.mx/turismocultural/cuadernos/pdf/cuaderno9.pdf

Martínez, M. (2005). El método etnográfico de investigación. Caracas: Universidad Simón Bolívar. Recuperado de http://prof.usb.ve/miguelm/ metodoetnografico.html 
Muñoz, E. (2011). Entre la vocación turística y la devoción. Percepciones sociales del patrimonio cultural en un contexto turístico. El caso de Malinalco, Estado de México. PASOS, Revista de Turismo y Patrimonio Cultural, 9(1), 115-127. Recuperado de http://www.pasosonline.org/ Publicados/9111/PS0111_10.pdf

Osorio, M., Cruz, G., Garduño, M., López, A., Miranda, G., Espinosa, G. y Vallejo, B. (2016). Chalma: la oportunidad de desarrollo turístico de un destino religioso. En J. Trujillo (comp.), Casos de investigación turística aplicada en México (pp. 46-70). Tuxtla Gutiérrez: Universidad Autónoma de Chiapas.

Parker, C. y Moreno, A. (2015). Turismo indígena urbano, innnovación identitaria? Atenea, 512. Recuperado de http://www. scielo.cl/scielo.php?script $=$ sci_arttext\&pid $=$ S0718$04622015000200013 \&$ lang $=p t$

Pérez, F. (29 de julio de 2015). Pobladores demuelen templo en Tlaxcala catalogado como inmueble histórico. Excélsior. Recuperado de http:// www.excelsior.com.mx/expresiones/2015/07/29/1037304

Prats, L. (2005). Concepto y gestión del patrimonio local. Cuadernos de Antropología Social, 21, 17-35. Recuperado de http://www.redalyc.org/ articulo.oa?id $=180913910002$

Querol, M. (2010). Manual de gestión del patrimonio cultural. Madrid: Akal.

Robles, J. (8 de octubre de 2001). Turismo religioso. Alternativa de apoyo a la preservación del patrimonio y desarrollo. Revista Bibliográfica de Geografía y Ciencias Sociales, 316. Recuperado de http://www.ub.edu/ geocrit/b3w-316.htm

Romo, J. (2004). El uso turístico del espacio religioso: el santuario de Loiola en la "Ruta de los Tres Templos". Universidad de Deusto, Instituto de Estudios de Ocio. Recuperado de http://www.industria.ejgv.euskadi. eus/r44-tu0014/es/contenidos/informacion/8007/es_2595/adjuntos/loiola_01.pdf

Rosas, A. (2003). Los usos del patrimonio cultural en el Centro Histórico. Alteridades, 13(26), 35-43. Recuperado de http://www.redalyc.org/ articulo.oa?id $=74702604$ 
Sánchez, A. (2013). Dos ferias toluqueñas: El Carmen y la Merced. En Las siete Tolucas y otros ensayos. Toluca: Instituto Municipal de Cultura, Turismo y Arte.

Santillán, R. y Olmos, H. A. (comps.). (2004). El gestor cultural. Ideas y experiencias para su capacitación. Buenos Aires: Ediciones CICCUS.

Sectur. (2012). Conoce los 11 pueblos mágicos de México. México: Autor. Recuperado de http://www.pueblosmexico.com.mx/

Sectur. (2015). Turismo Cultural. Gobierno de la República. Recuperado de http://www.sectur.gob.mx/hashtag/2015/05/14/turismo-cultu$\mathrm{ral} /$

Thompson, J. (2006). El concepto de cultura. En Ideología y cultura moderna. Teoría crítica social en la era de la comunicación de masas (pp. 183240). México: Universidad Autónoma Metropolitana-Xochimilco.

Torija, A. (24 de noviembre de 2015). El Patrimonio Cultural: guerra, contrabando y destrucción. Esglobal. Recuperado de https://www.esglobal. org/el-patrimonio-cultural-guerra-contrabando-y-destruccion/

Unesco. (1982). Conferencia mundial sobre las políticas culturales. México: Autor. Recuperado de http://unesdoc.unesco.org/ images/0005/000525/052505sb.pdf

Unesco. (2003). Declaración de la UNESCO relativa a la destrucción intencional del patrimonio cultural. París: Autor. Recuperado de http:// portal.unesco.org/es/ev.php-URL_ID $=17718 \&$ URL_DO $=$ DO_ TOPIC\&URL_SECTION $=201$.html

Unesco. (2005). Convención sobre la protección de la diversidad de las expresiones culturales 2005. París: Autor. Recuperado de http://portal.unesco. org/es/ev.php-URL_ID $=31038 \& U R L \_D O=$ DO_TOPIC\&URL_ SECTION $=201$. html

Velasco, M. (2009). Gestión turística del patrimonio cultural: enfoques para un desarrollo sostenible del turismo cultural. Madrid: Universidad Complutense de Madrid, Centro de Estudios Superiores Felipe II. Recuperado de http://www.redalyc.org/articulo.oa?id = 39811874012 